\title{
SUSTAINABLE IMPROVEMENTS FOR CUSTOMIZED PLATFORM EFFECTIVENESS IN GARMENT PRODUCTION
}

\author{
Yong $\mathrm{Ji}^{1}$, Gaoming Jiang ${ }^{1, *}$, Honglian Cong ${ }^{2}$ \\ ${ }^{1}$ Engineering Research Center for Knitting Technology, Ministry of Education, Jiangnan University, Jiangsu, Wuxi, 214122, China \\ ${ }^{2}$ International Joint Research Laboratory for Noval Knitting Structural Materials at Jiangnan University \\ E-mail: jgm@jiangnan.edu.cn
}

\begin{abstract}
:
This study uses sustainable development theory to analyze China's garment industry, which has been under pressure of high energy consumption, excess capacity and environmental pollution. The purpose of this work is to explore customized platform effectiveness on fashion design and production by the integration of clothing ceo-design (CED) and clothing life cycle evaluation. By cooperation and data analyses, garment companies come into being, which provides information for the study on customized platform effectiveness. Meanwhile, this paper begins with addressing the potential problems for fashion design, production and inventory management, making a distinction between garment virtual design (GVD)and personalized garment customization (PGC) and suggesting a useful computer-aided approach for fashion design and production process. The data and information were gathered from garment companies in China. This work presents the findings from case study research into sustainable improvements for fashion design and production in the garment industry; in this way, the level of customized platform may be compared and analyzed, which is a significant growth point of sustainable improvements for this research and practice domain.
\end{abstract}

\section{Keywords:}

customized platform, garment virtual design, personal customization, sustainable production

\section{Introduction}

The labor cost, eco-design and cleaner production of textile industry are the important aspects of every garment enterprise. In the mobile Internet era, consumers need to customize their own clothes, whereas garment enterprises need low-energy, low-loss and environmentally friendly manufacturing process [1]. However, a few China's garment companies are forced to attempt to adopt computer-aided customized techniques to keep the environment clean and minimize material utilization [2]. Second, due to the backward production techniques, many garment companies have suffered from raw material loss and environmental pollution [3]. The problems existing in fashion design and manufacturing process of industrial are presented in Figure 1.

Previous studies have shown that more than 28 million tons of clothing are discarded in China every year [3], and due to ever-tougher competition, garment manufacturers could be tempted to sacrifice environmental protection to dispose the undecomposed garments that cause environmental pollution [4]. According to the China environmental protection organization, the entire garment industry chain is the second most polluting industry after the energy sector, and a large number of the discarded garments and household refuse are drowned together and cannot be degraded and hence cause pollution. In order to improve the sustainability performance of garment industry, clothing ceo-design (CED) has to be considered in sustainable improvements for a customized platform [5].
CED refers to the premise of ensuring the use function, product quality and service life of clothing products to reduce pollution impact as much as possible during the process of design and production [6]. Through the rational utilization of resources and energy, the recovery rate can be improved to minimize the damage to the environment. Clothing companies have gradually realized the importance of customized platforms and started to join in CED [7]. However, due to the limitations of design and manufacturing of most garment companies in China, there is potential value in finding ways for fashion design and manufacturing for adjusting to such changes.

To enable reform of the clothing industry toward sustainable customization of CED should be driven by the new production model with big data, intelligent manufacturing and 3D fitting development of technology [8]. In addition, flexible supply chains are being built by more and more clothing companies to reduce manufacturing costs and shorten custom cycles, making mass customization possible, which hinders the clean and sustainable development of the garment industry [9]. In addition, the long production process and the increase in fabric loss rate affect the sustainable production of clothing. Driven by information interaction of consumers with garment companies and industrial chain collaborative supply platforms, the garment industry chain will gradually become an ecological chain of openness, sharing and ecology, and garment virtual design (GVD) is the development direction of the customized platform field [10].

Sustainable development together with personalized garment customization (PGC) of the customized platform can have a 


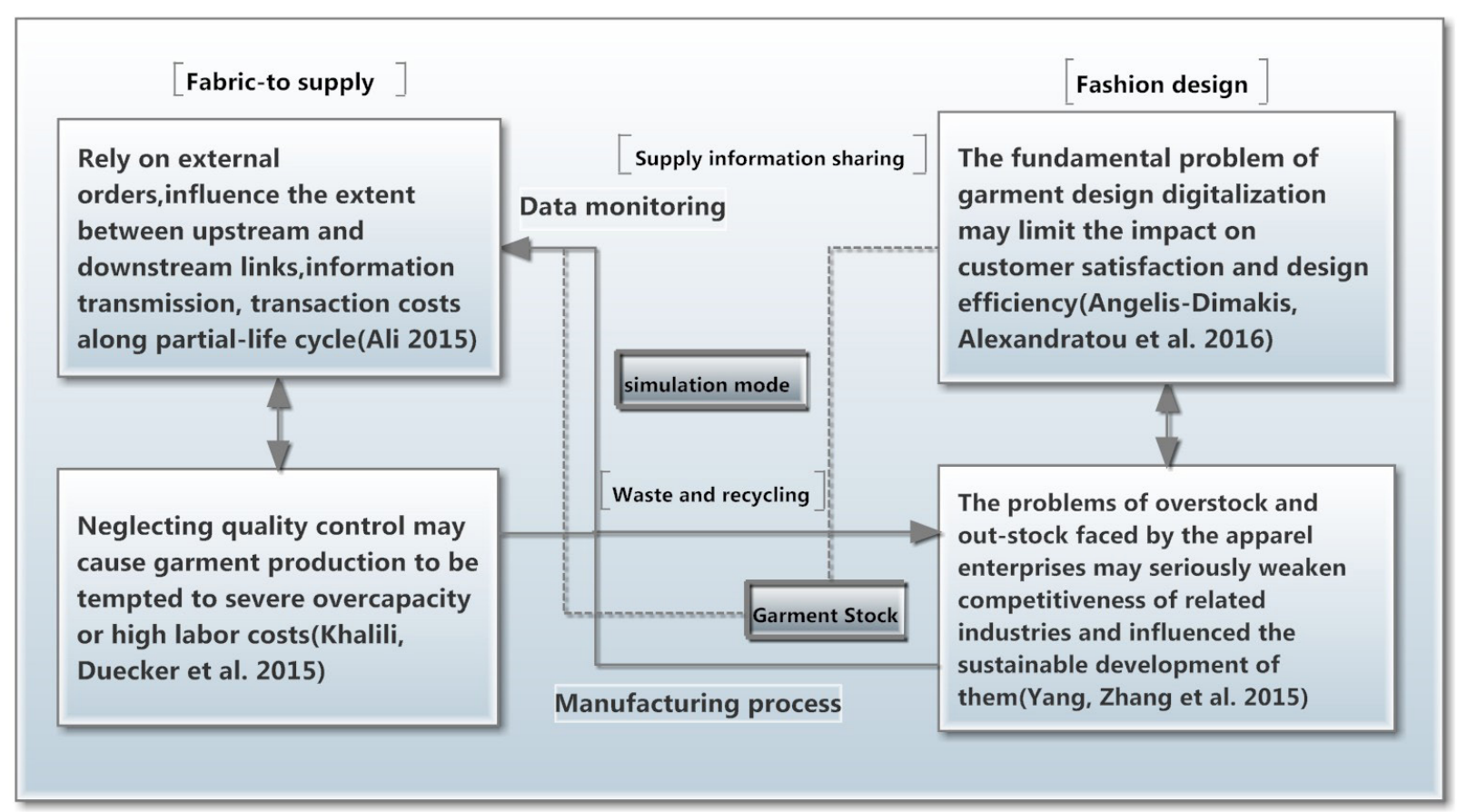

Figure 1. Sustainability issues for design and production limit in garment industry

strong influence on PLCE, which is one of the solutions to the problems facing the high pollution and high energy consumption of Chinese society [11]. For garment companies, customized platform is a good way to achieve sustainable development that can save energy, materials and other aspects of consumption, especially to reduce the emission of environmental pollutants [12]. From the perspective of the sampling inspection report of the state quality inspection organizations, there are a large amount of low-quality clothing as a waste to throw away [13]. However, the traditional production way of high energy consumption and high pollution has many problems, which has lost the recognition and support of the government and consumers, hindering the sustainable development of the garment industry [14].

A number of researchers in the literature have addressed that the inventory caused by homogenization has a destructive effect on China's garment industry chain. The application of customized platforms can affect CED leading to energysaving or environmentally friendly production [15] and finally can reduce more pressure of pollution of the existing clothing inventory and raw material loss [16]. This study mainly concerns the GVD in the clothing design and production of customized platform, focused on Chinese garment companies whose design and production in China, procurement of raw material from China or Europe.

This article focuses on garment companies with their design and manufacturing placed in China. Both of them want to realize sustainable improvements for customized platform effectiveness. Based on this, the study of application of computer-aided customized platforms can not only meet the demand of green garment production but also combine the product customization and order management to create more effective CED mode, provide reference for the sustainable development of the garment industry. However, China's environmental performance will face even worse if it does not effectively control pollution in the future garment industry [2].

\section{Literature review}

Researchers have proposed various approaches for customtailor service (CTS), considering environment complexities, and include the integration of PGC, quick response manufacturing, customer order decoupling point and modularization operations $[15,17]$. Flexible supply chains are being built to reduce production cost and shorten custom cycles, making mass customization possible, which indicates sustainable development of the garment industry (Alfirevic, Rendulic et al. 2015), the potential for multiple garment cycle of clean production systems, making a distinction between GVD and customized platform. For an overview, please refer to the studies of Guo et al. and Meng et al. $[18,19]$. The study focuses on GVD, and accordingly, the literature is segmented into three parts. First part leans forward toward CED. Second discusses application experience of GVD and PGC in the customized platform and selected studies from smart garment ecosystem. The third section discusses summary, application and gap areas.

\subsection{Impact of CED on the customized platform}

As argued by Guo et al. [18], a cloud-based intelligent decisionmaking system was developed to tackle CED, which combined cloud computing technologies to capture real-time production records and make remote production order tracking and employed computational intelligence techniques to generate effective order allocation solutions to apparel manufacturing.

CED has been widely recognized to identify how ecodesign techniques can be determined as being compatible with new product development processes [20]. 'Applicability framework' 
was used to identify CED techniques. The CED applications may not have been more widely adopted by businesses because such methods are not inevitably generic and immediately applicable. In CED, the product development process can also act as a barrier to adoption, and the complete integration of eco-design techniques will have to involve approaches that overcome such pressures.

While, the advantage of CED has worked to reduce negative social and environmental impacts [6]. They point out that many companies look to ecolabelling schemes as a means to set performance criteria and to demonstrate progress to customers. This viewpoint is supported by investigating the connection between ecolabels and CED from the perspective of moving the garment industry toward sustainability. That is, a more sustainable textile industry could have a base on expanding the expertise and information already in CED regarding sustainability of clothing finished products [18]. Such sustainable development is only possible if the designers can be guided by CED for the company.

Sakao, Fargnoli (2010) revealed that CED is intended to mean 'the approach that manufacturers adopt for the purpose of marketing eco-designed products.' At this juncture, CED should include the value of the product from the customer perspective and also contain environmental characteristics as one important element of a CED product [21]. They found that it is important to identify systematic connection, which is developed to make the value of the environmental characteristic appreciated by customers. In line with the introduced 'augmented' in the ecodesign process, CED is pivotal opportunity for companies' success, enabling designers to deepen the information of concerned customers. In fact, this CED approach has been investigated into the use of environmental quality function deployment by Sakao (2007). It is also suggested that CED approaches need to propose tools that incorporate customer requirements in parallel to environmental requirements at an early stage of product design.

\subsection{The application of GVD and PGC on the customized platform}

GVD can be made up of material properties and external interactions through a particle-based cloth model embedded in constrained Newtonian dynamics with anti-collision algorithm extended to complex-shaped garments [22]. They can take incorporate model within a 3D graphical environment, which includes operators monitoring the whole design process of apparel. Researchers [23] introduced 'solution techniques' for a 3D Made-to-Measure scheme for apparel products.

A few studies $[19,24]$ have considered the PGC to generate user customized apparel products with an optimization framework to match their original shapes locally while interpolating the shape of features determined for individuals with variant body shapes. They also have proposed an automatic body measurement system for virtual try on of a designed garment. But, it is observed that the scanning system and its application software need to enable apparel manufacturers to consumers seeking personal-fit garments for apparel mass customization.
During a wearer's movement in PGC, the apparel fabric layers collide each other in a highly complicated manner [25]. They have compelled collisions to examine key points involved in cloth-cloth and cloth-body collision. The multiplicity of the textile fabrics, including silk, wool, cotton and other synthetic fibers, together with the complex details of the apparel construction, makes the collision and other calculation procedures involved in PGC much more complicated.

\subsection{Summary of research review, application and gap area review}

CED has become a challenging approach and an 'accepted design consensus'. The cloud-based intelligent decision-making system was adapted to cope with the recession of CED, which captures real-time production plan and make personalized customization platform tracking to generate effective mass customization solutions to apparel manufacturing. The CED applications may not have been more widely adopted by clothing manufacturer because such methods are not inevitably generic and immediately applicable. It emphasizes on the product development process, which can also act as a barrier to adoption, and that the complete integration of eco-design techniques will have to involve approaches that overcome such pressures. A more sustainable textile industry should be based on minimizing resources consumption, wastes, cycle time and emissions in CED regarding sustainability of clothing finished products. Accordingly, it can be understood and accomplished in many different modes.

Typically, CED through GVD, focusing on the implementation of these methods, depends on the consumer requirements when one deal with complex manufacturing environment. GVD is important to identify systematic connection, which is developed to make the value of the environmental characteristic appreciated by customers, and provide opportunity for companies' success, enabling designers to deepen the information of concerned customers. However, GVD approaches need to propose tools that incorporate customer requirements in parallel to environmental requirements at an early stage of product design, but face a lot of difficulty due to the lack of PGC large-scale use in mass customization. PGC can be made up of incorporate model within a 3D graphical environment and includes operators monitoring the whole design process for a 3D Made-to-Measure scheme for apparel products. Those general principles have been considered to generate usercustomized apparel products with an optimization framework to match their original shapes locally in PGC which in turn complicates PGC applications. Visualizing complexities of GVD and PGC processes, there seems to be a strong demand for a simple and easy to apply, PGC-based study for achieving a customized approach for CED on the customized platform. This study addresses these gap areas.

\section{Methods}

To inspect the role of GVD in the customized platform, first in clothing industry, it is necessary to recognize the role of PGC in the process of costume design and production. Among them, 
Table 1 General information about the four clothing companies investigated in China

\begin{tabular}{|c|c|c|c|c|}
\hline \multirow{2}{*}{ Founded } & Company A & Company B & Company C & Company D \\
\cline { 2 - 5 } & 1990s & $\mathbf{2 0 0 0 s}$ & 1990s & 1990s \\
\hline Range & $\begin{array}{c}\text { Career apparel for men } \\
\text { and women plus }\end{array}$ & $\begin{array}{c}\text { Everyday apparel for } \\
\text { men, women and kids }\end{array}$ & $\begin{array}{c}\text { Everyday apparel for } \\
\text { men and women }\end{array}$ & $\begin{array}{c}\text { Everyday apparel for } \\
\text { men and women }\end{array}$ \\
\hline $\begin{array}{c}\text { Number of } \\
\text { employees }\end{array}$ & $200-400$ & $500-700$ & $300-500$ & $100-300$ \\
\hline Number of stores & 29 & 22 & 18 & 13 \\
\hline $\begin{array}{c}\text { Total revenue 2015/ } \\
\text { million RMB }\end{array}$ & $60-80$ & $200-300$ & $100-200$ & $<5$ \\
\hline
\end{tabular}

Table 2 Adapted PGC for matching analysis on the customized platform

\begin{tabular}{|c|c|c|c|c|c|}
\hline \multirow{2}{*}{$\begin{array}{c}\text { Customized platform } \\
\text { metrics }\end{array}$} & $\begin{array}{c}\text { Personal } \\
\text { customization }\end{array}$ & Virtual sample & Virtual fit & $\begin{array}{c}\text { Garment } \\
\text { sample making }\end{array}$ & $\begin{array}{c}\text { Clothing mass } \\
\text { production }\end{array}$ \\
\cline { 2 - 6 } & 4 & 3 & 1 & 3 & 4 \\
\hline Material purchase & 3 & 4 & 5 & 2 & 3 \\
\hline Product design & 2 & 5 & 4 & 1 & 3 \\
\hline Production-manufacturing & 2 & 2 & 3 & 3 & 3 \\
\hline Inventory control & 3 & 1 & 4 & & 2 \\
\hline
\end{tabular}

PGC, personalized garment customization.

the reference data on the consumption side come from online information and related literature. The data of the customized platform on the production side come from four clothing companies as shown in Table 1. Due to clothing equipment and design concepts lag behind, advanced garment production way permeability is not high in China [26]. Companies based on PGC phases are listed in Table 2. The raw material loss, design process loss and stock quantity of each custom garment are the basis data reference comparison. The product life cycle based on big data clothing customized company and traditional design company is used as the basis reference data comparison. According to the five aspects of PGC phase on the customized platform in Table 2 compared with the traditional garment design process, there will be presentations on conducting CED research, inventory management systems, the intersections of PGC, design methods and virtual fit, tech for clothing mass production and so on.

Then, in order to assess the PGC role in the CED process, much work has been carried out on the interview consisted of four management personnel of clothing companies [27], one of whom did not use GVD, the rest have focused on the development of virtual design methods and tools that are intended to assist designers in adapting their product for ease of garment customization, which had formed the custom mode based on big data of cloud computing integrating customer service including customer size and dress preferences [28]. However, most of the clothing companies are not yet aware of the use of customized platform.

Based on the evaluation results of GVD of consumer customization mode, the paper needs to analyze the PGC process on the customized platform and the life cycle of clothing products. From the perspective of data analysis, customized platform targets on the requirement analysis of customization flows to the garments and the abstraction of the data-to-object model adapted from the method of Malleson 2013, compared with related literature, the conclusion of the method of GVD was obtained.

\section{Result}

This section presents instance study findings from the customized platform sector. In Section 3.1, the range of CED in textile and apparel products is described. In Section 3.2, GVD processes of clothing products in three garment companies are reported. Then, in Section 3.3 based on PGC studied and empirical results from six companies, clothing products with sustainability performance of their life cycle are compared.

\subsection{The range of CED in apparel companies}

CED used in apparel companies not only cover all life cycle stages of garment products but also focus mainly on GVD in the clothing customization chain [29]. As a result of $t$-test in company A, null hypothesis was set to " $80 \%$ of the opinions are in support of successful integration of CED and personal customization for ensuring sustainable CED at $95 \%$ confidence interval". The results of $t$-test are interpreted in Table 3 . Through observation, $p$ value is greater than 0.05 , which indicates the receiving side of null hypothesis. 
Table $3 t$-test of company A application of clothing ceo-design on customized platform

\begin{tabular}{|c|c|c|c|c|}
\hline Types & Grace period (months) & No & Rate of count reduction (\%) & Cost formula (USD) \\
\hline Material & 12 & 1 & 30.2 & $(173.652,123.529)$ \\
\hline Inventory & 12 & 1 & 23.8 & $(2.623 .429,2.225 .843)$ \\
\hline Labor & 12 & 1 & 18.5 & $(137.237,106.461)$ \\
\hline
\end{tabular}

Table 4 Economic date for company A application of clothing ceo-design on customized platform

\begin{tabular}{|c|c|c|c|c|c|c|c|}
\hline Variables & $\mathbf{N}$ & Mean & Deviation & Standard error of mean & $\mathbf{9 5 \%} \mathbf{C l}$ & $\mathbf{t}$ & $\mathbf{p}$ \\
\hline Less material usage & 3 & 6.565 & 0.577 & 0.333 & $(5.232,8.101)$ & -3.00 & $0.321^{\#}$ \\
\hline Less design process & 3 & 7.623 & 1 & 0.577 & $(6.516,10.484)$ & -1.76 & $0.132^{\#}$ \\
\hline Less inventory & 3 & 5.691 & 0.577 & 0.333 & $(5.899,8.768)$ & -2.00 & $0.217^{\#}$ \\
\hline Easy to transport & 3 & 6.792 & 0.577 & 0.333 & $(6.232,9.101)$ & -3.00 & $0.125^{\#}$ \\
\hline
\end{tabular}

Table 5

\begin{tabular}{|c|c|c|c|}
\hline & Before PGC & Set PGC at 12 months & \% different \\
\hline Fabric used & 6.03 & 4.79 & 20.56 \\
\hline Design process & 3.72 & 3.15 & 15.32 \\
\hline Material recycle & 2.42 & 1.97 & 18.60 \\
\hline Inventory & 5.64 & 3.81 & 32.45 \\
\hline Labor consumption & 2.61 & 2.27 & 13.03 \\
\hline
\end{tabular}

Comparison of optimal results of PGC for company $C$.

PGC, personalized garment customization.

In these covered companies as shown in Table 4, when company A sets the PGC period limit at 1 year (12 months), the net annual fabric saving was reduced to USD 123,529/year with the minimum number of fabric consumption and material generation decreased from $96,231 \mathrm{~m} / \mathrm{y}$ to $67,169 \mathrm{~m} / \mathrm{y}$. This gave reductions of $30.2 \%$ of fabric. The PGC is also favored to reduce $18.5 \%$ of the labor costs because it is convenient in terms of mass customization as compared to erasure of apparel stock that was $23.8 \%$. At the same time, the total regenerated labor consumption was significantly decreased when PGC limit was set to 1 year, and it is all because, the inventory management is the most intelligentialize needed among all PGC process change options. As shown in Table 4, the improved design method of PGC has overcome the unstable phenomenon within certain degree so that the range of application is enlarged as follows: fabric used stage, costume design stage, material recycle stage, inventory management and labor consumption stage, and in CED, the performance of garment life cycle will correspond to the reduction of clothing customization and production process.

\subsection{The GVD process in mass customization}

The four clothing companies investigated use an open architecture including procurement, design, production, sales and warehousing that allows for a high degree of customization to match the customer's business processes and to integrate with the existing back-end design system. Then, as the basis of mass production, companies $A, B$ and $C$ have their own virtual design centers with GVD software of customized platform, produce clothing virtual sample and the PGC as order communication with customers in the middle of the process; company $D$ also introduced the PGC, but did not use GVD as part of the customer order service; and the 2D apparel design generated was almost the majority of clothing customization.

Figure 2 analyzes the impact regarding product design steps in which the clothing companies particularly invest in effort to clothing life cycle. As seen in Figure 2, the dotted line can be used to compare the performance of GVD instance between different companies. Companies $A, B$ and $C$ have GVD in the whole clothing product design steps. Company $A$ has clear comparative advantage on GVD functionality in its fabric use and product design and has used the garment virtual samples to a large extent on the production including the early product creative design and the final mass production through the 
whole process of designers and production. Companies $B$ and $C$ also put GVD as one of the core links of the whole enterprise design and production, but it is little less effective than $A$ on GVD. In subsequent link of product life cycle, most important of all, Figure 2 shows that four clothing inventory performance of pollution to the environment, where company $D$ has produced large clothing inventory, the retention of clothing was as waste management, produce the pollution to the environment.

\subsection{Comparative analysis of PGC with the customized platform}

All the four companies provide PGC attached to the customized platform that aims to increase the availability of customized service based on the customer wearing hobby by 3D body scanner inputting customer body data [30]. In order to create a personal profile and provide clothing customization services, the PGC model on the customized platform as shown in Figure 3. It can be seen from Figure 2 and Table 5 that through ongoing efforts, company $\mathrm{C}$ improves order reaction to changing production requirement to keep inventory fall to
$32.45 \%$ and awaits more operations to transition from being a manufacturer to the Internet-based services by the application including mobile internet, cloud computing, big date and garment virtual sample as Figure 4, this gave reductions of $15.32 \%$ of the costume design process. On this basis, through GVD cooperated with PGC in 3.2, company $C$ also goes on standardization of purchasing and supply management to reduce by as much as $20.56 \%$ of fabric and also has a deposit recycling system on their garments. At the same time, company $C$ provided by customizes platforms is not only for the general consumers but also for the enterprise groups, which product sales are the strongly performance-defined by the control of fabric and inventory.

On the contrary, company $D$ only provides traditional offline PGC for enterprise groups or individual consumers, and the fabric that is returned for manufacturing cannot be recycled or disposed of in a proper way [31], which is illustrated as a high inventory for waste and pollution in Table 1. Consequently, due to the lack of GVD, the other traditional garment companies also face waste and pollution [32] of clothing more serious

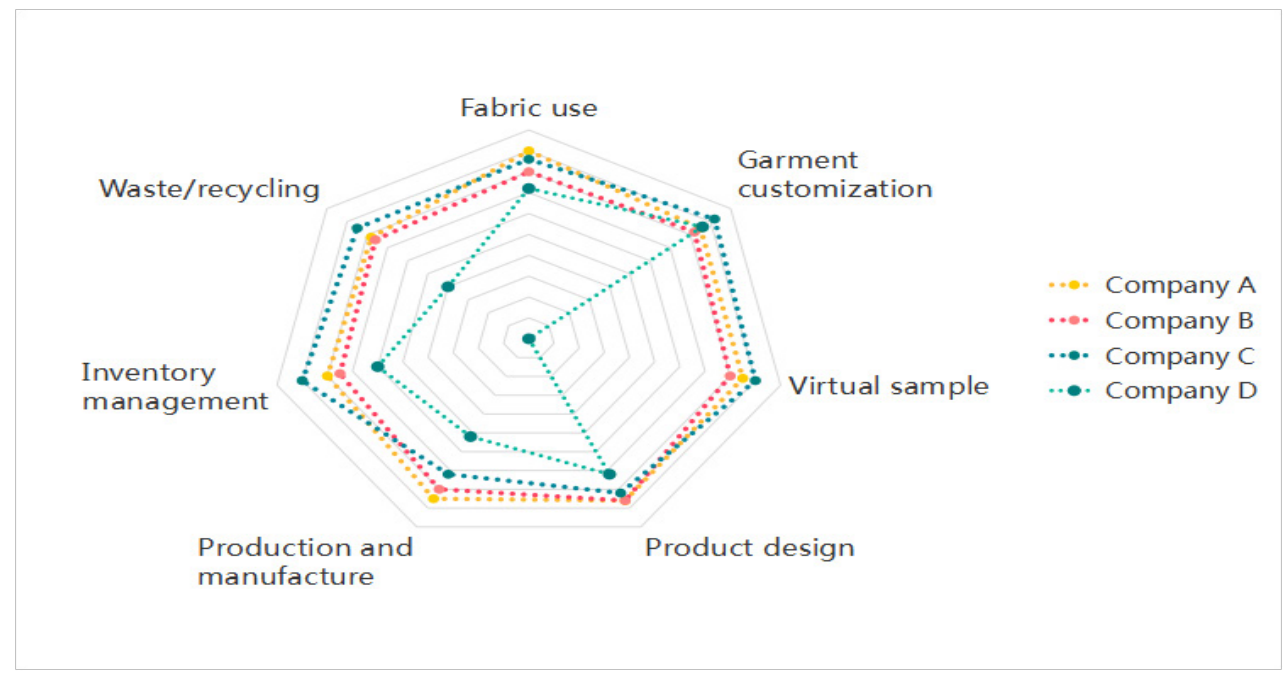

Figure 2. The performance of garment virtual design process in four companies

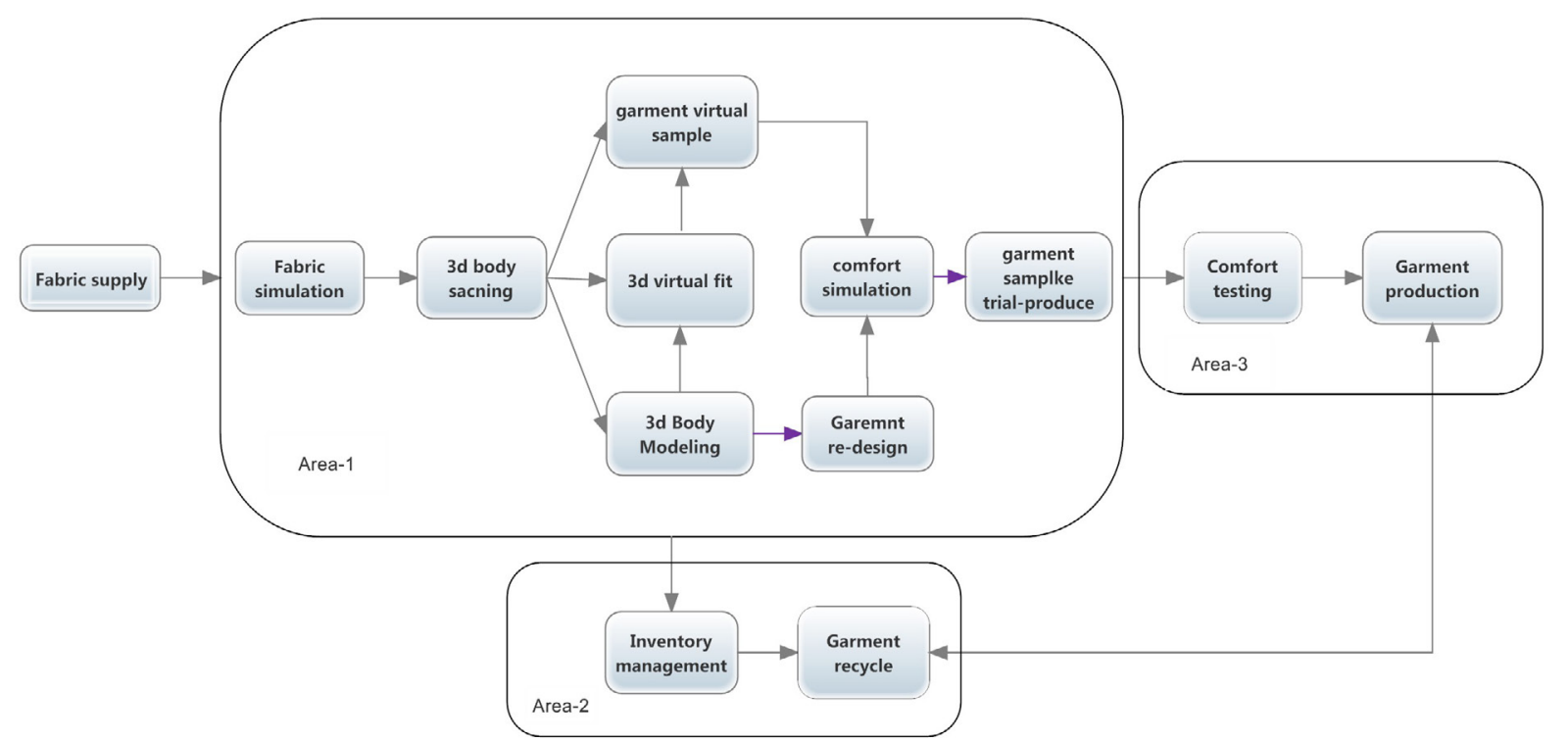

Figure 3. Personalized garment customization model on the customized platform 
than other companies, which provide negative effect scale for themselves to realize CED and clean production.

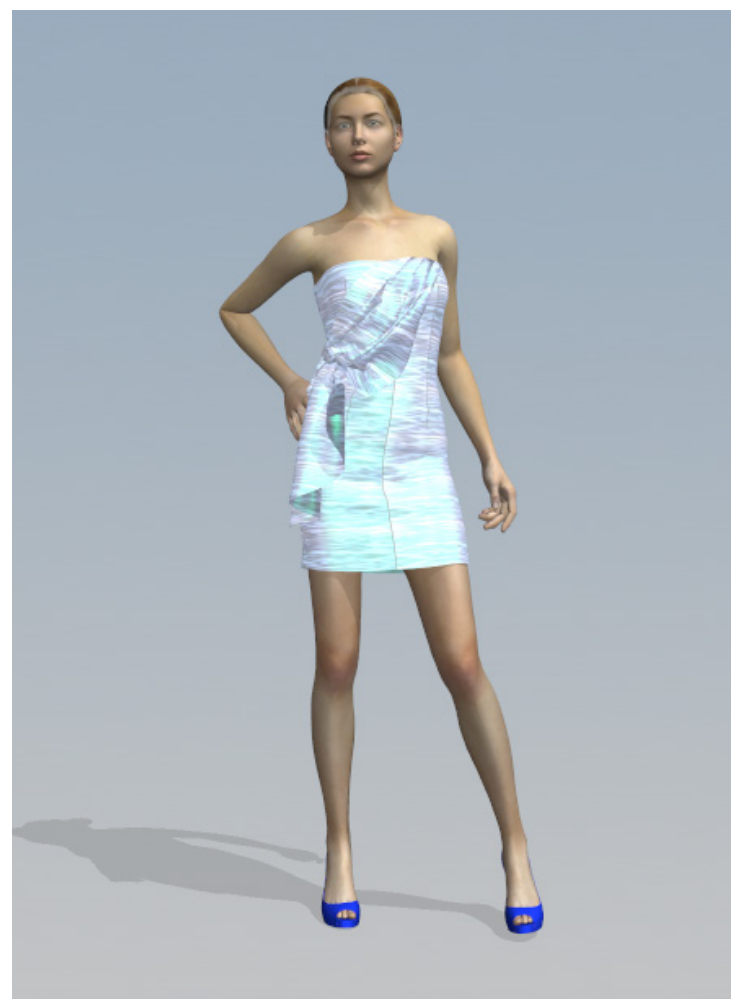

Figure 4. Garment model on the customized platform

\section{Conclusion and future research}

This paper studies the customized platform and assessment system of garment and provides theoretic basis and data support for realizing sustainable development of clothing industry. This method achieves GVD than 2D design, which is based on a rigorous and simple PGC process. Therefore, the customized platform can provide more flexible product line of clothing design and manufacture on the basis of multiscale and data representation. Consequently, any form of clothing custom process can be obtained by it.

After the acquirement of several groups of GVD, these companies will be classified as transitional companies and custom companies based on the design and processed method. Then, the promising PGC is selected to reconstruct the design method, which will be formed by the customized platform. The final evaluation result will be obtained through the clothing design and production of four companies. In the context of this study proposed, the authors were able to identify the following prioritized order of customized platform effectiveness factors as follows:

-Material recycle

- Inventory

- Design process

-Fabric used

- Labor consumption

The resulting implications are that the approach utilized in this paper highlights a technique for garment industry to explore sustainable improvements and prioritize scope assessment.
As a result, the customized platform underpinned by big data technologies will give producing chain partners the support that GVD is being adopted to reduce dependencies on plate making and inventory, thus promoting sustainable source future and carbon-efficient production. The appraisal of those factors that promote CED through this paper now provides companies with the sustainable improvements for the customized platform that offers them elaboration against a backdrop of efficient and effective sustainable operation production.

Although systematic literature review and case studies help the industrialists and entrepreneurs to better develop a sustainable garment production, there are several limitations to the abovementioned research. First, this paper selects only four companies to investigate the effectiveness of the customization platform, which may not have detailed about a sustainable customization platform. For future research, more details in sustainable computer-aided customized design and production should be explored. Second, in the case study, due to the complexity of design and production systems, four companies cannot represent the whole of the garment product design and production process. For future research, the topic of sustainable customized platform modularization should receive long-term attention.

\section{Acknowledgments}

The authors acknowledge the financial supports from the National Science Foundation of China (No. 11302085 and No. 51403080), the Fundamental Research Funds for the Central Universities (No. JUSRP51404A) and the Postgraduate Research \& Practice Innovation Program of Jiangsu Province (No. KYCX18-1828).

\section{References}

[1] Yang, G., Zhang, G., Wang, H. (2015). Current state of sludge production, management, treatment and disposal in China. Water Research, 78, 60-73.

[2] Yong, J. Y., Klemeš, J. J., Varbanov, P. S., Huisingh, D. (2016). Cleaner energy for cleaner production: Modelling, simulation, optimisation and waste management. Journal of Cleaner Production, 111(8), 1-16.

[3] Wang, J., Ning, X., Ruijing, L. I., Wen, W., Yang, Z., Ruizhe, H. E., Liu, J. (2015). Pollution characteristics of aromatic hydrocarbons and ecological risk assessment of the sludge in the typical textile dyeing wastewater treatment process. Environmental Chemistry, 34(6), 1201-1208.

[4] Subic, A., Shabani, B., Hedayati, M., Crossin, E. (2013). Performance analysis of the capability assessment tool for sustainable manufacturing. Sustainability, 5(8), 35433561.

[5] Peterson, J., Mujanovic, M., Mattila, H. (2015). Mass customisation of flat knitted fashion products: Simulation of the co-design process. Autex Research Journal, 11(11), 6-13.

[6] Yuen, C. W. M., Fung, E. H. K., Wong, W. K., Hau, L. C., Chan, L. K. (2008). Application of smart system to textile industry: Preliminary design of a smart hanger for garment inspection. Journal of the Textile Institute Proceedings \& Abstracts, 99(6), 569-580. 
[7] Arun, K. N. (2012). Production planning module of erp for small scale industry. International Journal of Production Technology \& Management.

[8] Wang, J., Lu, G., Chen, L., Geng, Y., Deng, W. (2010). Customer participating $3 D$ garment design for mass personalization. Textile Research Journal, 81(2), 187-204.

[9] Alfirevic, N., Rendulic, D., Talaja, A. (2015). Application of a cloud-based supply chain management system to achieve mass customization: Best practices from the automotive industry. Monthly Notices of the Royal Astronomical Society, 206(1), 19-35.

[10] Meng, Z., Lu, J. (2016). A rule-based service customization strategy for smart home context-aware automation. IEEE Transactions on Mobile Computing, 15(3), 558-571.

[11] Chakraborty, D., Mukhopadhyay, K. (2014). Status of water pollution in India and other countries of Asia. Neurobiology of Disease, 4(s 3-4), 311.

[12] Gungor, M., Agac, S. (2014). Resource-constrained mixed model assembly line balancing in an apparel company. Tekstil Ve Konfeksiyon, 24(4), 405-412.

[13] Spahija, S., Shehi, E., Guxho, G. (2012). Evaluation of production effectiveness in garment companies through key performance indicators. Autex Research Journal, 12(2), 62-66.

[14] Danskin, P., Englis, B. G., Solomon, M. R., Goldsmith, M., Davey, J. (2014). Knowledge management as competitive advantage: Lessons from the textile and apparel value chain. International Journal of Surgery, 12(4), 357-360.

[15] Biffe, D. F., Constantin, J., Oliveira, R. S., Franchini, L. H. M., Rios, F. A., et al. (2012). Personal garment rapid design based on customer online experience. Journal of Textile Research, 33(5), 145-149.

[16] Mari, S. I., Lee, Y. H., Memon, M. S. (2016). Sustainable and resilient garment supply chain network design with fuzzy multi-objectives under uncertainty. Sustainability, 8(10), 1038.

[17] Fujii, C., Takatera, M., Kim, K. O. (2016). Effects of combinations of patternmaking methods and dress forms on garment appearance. Autex Research Journal, 7(3).

[18] Guo, Z. X., Wong, W. K., Guo, C. (2014). A cloud-based intelligent decision-making system for order tracking and allocation in apparel manufacturing. International Journal of Production Research, 52(4), 1100-1115.

[19] Meng, Y., Wang, C. C. L., Jin, X. (2012). Flexible shape control for automatic resizing of apparel products. Computer-Aided Design, 44(1), 68-76.

[20] Cho, Y., Komatsu, T., Inui, S., Takatera, M., Shimizu, Y. (2006). Individual pattern making using computerized draping method for clothing. Textile Research Journal, 76(8), 646-654
[21]Zhong, Y. (2003). Three-dimensional technology for apparel mass customization: Part III: visualization of threedimensional garments. Journal of the Textile Institute, 94(1-2), 92-102.

[22] Yeung, K. W., Li, Y., Zhang, X. (2004). A 3D biomechanical human model for numerical simulation of garment-body dynamic mechanical interactions during wear. Journal of the Textile Institute Proceedings \& Abstracts, 95(1-6), 5979.

[23] Wang, C. C. L., Wang, Y., Yuen, M. M. F. (2005). Design automation for customized apparel products. ComputerAided Design, 37(7), 675-691.

[24] Xu, B., Huang, Y., Yu, W., Chen, T. (2002). Threedimensional body scanning system for apparel masscustomization. Optical Engineering, 41(7), 1475-1479.

[25] Lee, Y. J., Kim, J. J. (2011). A study on the drape profile analysis of the apparel textiles and $3 D$ virtual textiles using a $3 D$ digital clothing software. Astronomy \& Astrophysics, 15(5), 222-226.

[26] Wang, Z., Zhang, M., Sun, H., Zhu, G. (2016). Effects of standardization and innovation on mass customization: An empirical investigation. Technovation, 48-49, 79-86.

[27] Fu, M. C., East, E. W. (1999). The virtual design review. Computer-Aided Civil and Infrastructure Engineering, 14(1), 25-35.

[28] Jakhar, S. K. (2015). Performance evaluation and a flow allocation decision model for a sustainable supply chain of an apparel industry. Journal of Cleaner Production, 87(1), 391-413.

[29] Hong, Y., Bruniaux, P., Zeng, X., Liu, K., Curteza, A., et al. (2017). Visual-simulation-based personalized garment block design method for physically disabled people with scoliosis (PDPS). Autex Research Journal, 18(1), 35-45.

[30] Uhm, T., Park, H., Park, J. I. (2015). Fully vision-based automatic human body measurement system for apparel application. Measurement, 61, 169-179.

[31] Lomonaco-Benzing, R., Ha-Brookshire, J. (2016). Sustainability as social contract: Textile and apparel professionals' value conflicts within the corporate moral responsibility spectrum. Sustainability, 8(12), 1278.

[32] Angelis-Dimakis, A., Alexandratou, A., Balzarini, A. (2016). Value chain upgrading in a textile dyeing industry. Journal of Cleaner Production, 138, 237-247. 